\title{
疫情背景下线上线下混合式教学的思考一一高职《物流信息 管理》课程为例
}

\author{
王剑
}

苏州托普信息职业技术学院

DOI:10.32629/er.v3i7.2961

\begin{abstract}
[摘 要] 突发新型冠状肺炎病毒疫情,为了尽快战胜疫情,避免人群集聚,减少病毒传播,各地学校纷纷推 迟开学, 与此同时, 借助一些网络平台和资源, 开展线上课程。这给教师和学生带来了新的授课和学习的 体验,也对教学带了新的思考。本文基于以上背景,结合某高职院校的具体情况, 就《物流信息管理》这 门课程如何开展线上线下混合式教学进行探讨。
\end{abstract}

[关键词] 高职院校; 线上线下; 混合式教学

\section{1 课程概况}

《物流信息管理》课程是物流管理 专业的一门专业核心课程, 具有较强的 综合性、实践性和应用性。因此, 本门课 程的学习需要学生已经具备了一定的物 流基础知识和技能的基础上,才能更好 地开展学习。某高职院校将本门课程安 排在物流管理专业学生大二年级的下学 期, 也就是春、夏季学期, 时间为 18 个教 学周, 平均每周 3 课时, 共 54 课时。

\section{2 确定线上线下两阶段的教学内容}

线上学习主要依靠学生自主学习和 教师直播授课相结合的方式进行, 在教学 秩序、教学质量等方面的把控上存在一定 的不足。因此选择适合线上教学的课程内 容至关重要。根据线上教学的时间要求、 课程内容及安排, 选择一些基础理论知识, 或者对实训条件要求不多的实训环节等, 作为线上学习的内容。线上教学阶段结束 后, 继续开展线下教学, 那么, 需要注意保 证线下教学内容与线上教学内容的顺利、 有效衔接, 在线下教学过程中可以持续推 进线上线下混合式教学模式。

\section{3 线上教学设计}

3. 1直播课前。教师在直播前依托云班 课、智慧职教等平台, 发布学习任务, 上传 相关的PPT、微课视频、网页链接等, 学生 在手机端下进行查看, 根据教师的要求在
规定时间内完成学习和相应的作业。在此 过程中, 教师要密切关注学生的学习情况, 及时提醒学生跟上学习进度。教师在学习 结束后查看学生学习情况, 批阅学生作业。 另外, 教师要对于本章节的重难点、作业中 常见的问题等进行梳理, 为直播做准备。

3. 2 直播课中。教师借助QQQ群、腾讯 直播等平台开展直播。受时间和条件限制, 直播过程中可能难以做到面面俱到。在直 播过程中, 教师一方面要对直播前所梳理 的知识点进行充分讲解, 另外要留出足够 的时间为学生进行答疑解惑。线上学习最 主要还是依赖学生的自主学习, 那么在自 主学习过程中, 由于学生自身的知识基 础、认知结构、思维方式、学习动机等存 在差异, 在自学后会出现很多不同的问题, 那么教师在直播中要重视为学生答疑解 惑。一旦学生没有充分理解前面的知识点, 甚至带着问题继续往下学习, 那么后期的 线上学习将会难以继续。

3. 3直播课后。课后, 对学生的学习 效果进行检测和巩固, 了解学生对重难 点的掌握情况。教师在云班课、智慧职 教等平台发布作业, 如需要学生反复练 习, 加强巩固, 可以把练习次数设置为不 限次数。另外, 还可以发布实训作业, 学 生完成后以附件形式上传。

\section{4 线下混合式教学设计}

4. 1 课前阶段。第一次的线下教学得 课前阶段需要注意两点: 一是要注意与 前面的线上教学的内容衔接, 在线下面 对面教学前可以提醒学生对线上学习的 内容进行复习。另外, 督促学生对新知识 进行预习。这一阶段类似于线上的直播 课课前阶段, 上传资料, 发布学习任务, 学生课前进行预习。

4.2 课中阶段。第一次的线下教学可 以先对线上教学的内容进行复测, 比如 随机提问、课堂测试等。其次, 检查学生 对新知识的学习掌握情况。在此基础上, 对重难点以及出错较多的知识点针对性 的进行剖析。教师要建立生动的、多样 化的教学情境, 灵活采用小组讨论、团队 合作、情景模拟、实训演练、案例分析 等教学方法, 注重对学生的引导, 激发学 生的认知好奇心和学习动机, 让学生成 为学习的主体, 促使学生自主地发现问 题、探讨问题、解决问题。教师要把控 好整个课堂的秩序和学习进度。

4. 3 课后阶段。本阶段类似于线上直 播课后阶段, 注重对学生学习效果的评 估, 能力的拓展和知识的应用。

\section{5 线上线下混合式教学的实践案例}

疫情背景下, 面临一个多月的线上 教学和四个月左右的线下教学的要求。 就《物流信息管理》这门课程来说, 根据 
教学安排和教学内容, 前两个学习项目 可以进行线上教学。为展示线上线下教 学的连贯性, 本实践案例以两个衔接的 学习任务 “了解条码的基本知识” “掌握 商品条码”为例, 阐述线上线下混合式教 学的具体实施过程。

5.1 线上教学设计。

5. 1. 1直播课前。教师在云班课发布 相应的资源 (表1), 学生在手机端登入云 班课自主学习, 教师适时进行监督, 其中 有一份思考题需要学生在自主学习的基 础上完成, 并按时在云班课 “作业” 中以 附件形式提交。教师在直播课前批阅学 生的作业, 总结出学生容易出错的知识 点和本小节的重难点(表2)。

表 1 直播课前线上自学资料

\begin{tabular}{|c|c|c|}
\hline 序号 & 资料类型 & 资料名称 \\
\hline 1 & PPT 课件 & 条码技术概述. ppt \\
\hline 2 & 教学视频 & 条形码. mp 4 \\
\hline 3 & 文本资料 & 条码的起源及发展历史. doc \\
\hline 4 & 文本资料 & 条码技术概述-思考题. doc \\
\hline
\end{tabular}

\begin{tabular}{|l|l|l|}
\multicolumn{4}{c}{ 表 2 本小节知识点 } \\
\hline 序号 & 知识点 & 备注 \\
\hline 1 & 条码的结构 & 重点、难点 \\
\hline 2 & 条码符号的颜色搭配 & 易错点 \\
\hline 3 & 条码的编码方法 & 重点、难点 \\
\hline
\end{tabular}

5.1.2直播课中。本门课程选择的是 QQ群直播, 教师必须是群主或者管理员 的身份才能在 $Q Q$ 群进行直播。直播授课 过程中主要分成两个部分, 一是教师讲 授为主, 针对梳理出的易错点和重难点 (表2)采用不同的教学方法进行讲解 (表 3); 二是对学生自学过程中产生的问题 进行答疑解惑, 共同探讨。

\begin{tabular}{|c|c|c|}
\multicolumn{2}{c|}{ 表 3 直播课中的教学安排 } \\
\hline 序号 & 教学内容 & 教学形式 \\
\hline 1 & 条码的结构 & 教师讲授,图文结合 \\
\hline 2 & 条码符号的颜色搭配 & 教师讲授,总结规律 \\
\hline 3 & 条码的编码方法 & 教师讲授,对比归纳 \\
\hline 4 & 学生提出的疑问 & 集体讨论、教师引导、纠正、总结 \\
\hline
\end{tabular}

\begin{tabular}{|c|c|c|}
\multicolumn{2}{c|}{ 表 4 直播课后发布的资料 } \\
\hline 序号 & 资料类型 & 资料名称 \\
\hline 1 & 电子表格 & 条码技术概述-测试题. xls \\
\hline 2 & 视频 & 可口可乐: 会唱歌的条形码. flv \\
\hline 3 & 视频 & 能交流的条形码. mp4 \\
\hline 4 & 图片 & 趣味条码. png \\
\hline
\end{tabular}

5. 1. 3直播课后。教师在云班课发布 “测试” 任务 (表4), 设置完成时间。结束 后, 教师在云班课中查看测试结果, 学生 对错题进行订正, 教师在云班课添加 “答
疑/讨论” 活动, 师生一起讨论, 查缺补漏。 教师对教学过程和效果进行反思, 进一步 优化教学设计。此外, 发布课后拓展资料 (表4), 进一步激发学生的学习兴趣。

5.2 线下混合式教学设计。

5.2.1 课前阶段。学校开学后, 由 “纯” 线上教学转为线下混合式教学。 在这一阶段, 教师在云班课发布消息, 提 醒学生注意前阶段课程内容的复习, 同 时在云班课发布新课的相关资料(表5), 学生自主预习, 并完成“以小组为单位搜 集2-3个印有商品条码的不同商品包装, 并在下次课上进行展示” 的实训作业。 表 5 课前发布的资料

\begin{tabular}{|c|c|c|}
\hline 序号 & 资料类型 & 资料名称 \\
\hline 1 & PPT 课件 & 商品条码. ppt \\
\hline 2 & 视频 & 商品条码背后隐藏的秘密. mp 4 \\
\hline 3 & 文本资料 & 搜集常见商品条码包装-实训作业. doc \\
\hline
\end{tabular}

5.2 . 2 课中阶段

\begin{tabular}{|c|c|c|}
\multicolumn{3}{c|}{ 表 6 课中阶段教学安排 } \\
\hline 序号 & 教学内容 & 教学形式 \\
\hline 1 & $\begin{array}{c}\text { 前期已学内容复习 } \\
\text { 巩固 }\end{array}$ & 线上测试, 教师讲解 \\
\hline 2 & $\begin{array}{c}\text { 小组展示, 集体观摩、 } \\
\text { 讨论, 教师引常见 }\end{array}$ \\
\hline 3 & $\begin{array}{c}\text { EAN-13/EAN-8 商品条 } \\
\text { 条码 }\end{array}$ & $\begin{array}{c}\text { 图形对比, 集体” 找 } \\
\text { 若”, 线上讨论 }\end{array}$ \\
\hline 4 & 条码图形的绘制 & 教师示范, 学生练习 \\
\hline 5 & 知识点总结 & 教师总结、归纳 \\
\hline
\end{tabular}

表 7 课后发布的资料
\begin{tabular}{|c|c|c|}
\hline 序号 & 资料类型 & 资料名称 \\
\hline 1 & 文本资料 & 课后练习: 条码图形绘制与生成. doc \\
\hline 2 & 文本资料 & 商品条码如何在零售商品上的使用. doc \\
\hline 3 & 视频 & TNT 条码终端应用. mp4 \\
\hline
\end{tabular}

第一次线下教学的第一节课, 在云班 课中发起 “测试”, 对前面课程内容进行 综合测试。20分钟的小测试后, 对测试内 容进行讲解分析, 巩固前面所学的重难 点。第二节课, 开展新课的学习。学生以 小组为单位展示搜集到的不同商品包装 上的条码。在展示过程中, 其他同学进行 观摩、讨论, 辨别条码的类型, 分析条码的 特征。教师在云班课新增 “答疑/讨论” 活动, 上传EAN-13、EAN-8两种商品条码的 图片, 学生来 “找茬”, 展开讨论, 分析两 者的差异。在此基础上, 在教师的示范下, 学生练习条码图形符号的绘制。教师总结 条码的结构特点、编码方法 (表6)。

5.2.3 课后阶段。教师在云班课发布 课后学习资料 (表7), 学生根据课后练习的
要求绘制EAN-13商品条码3346470114746 的条码图形, 然后利用电脑在线生成条码 图形, 将自己手绘的条码图形与生成的条 码图形进行对比, 根据对比结果进行修改, 最后以附件形式在 “作业” 中上传对比图, 进一步提高学生的动手能力和学习兴趣, 为接下来的学习奠定基础。

\section{6 总结}

根据环境及条件的不同, 线上线下混 合式教学模式既可以拆分使用, 也可以组 合使用。比如, 一些兴趣课程可以全部采 用线上教学的方式进行, 感兴趣的学生进 行自主学习。平时在校的正常上课可以采 用线下混合式的教学方式。在目前疫情的 情况下, 更多的是采用前期线上教学, 后 期线下混合式教学的方式。某高职院校学 生的学习过程是 “工” “学” 交替的过程, 也就是学生的在校学习和企业实习这两 个环节循环交替的过程。“工” 和 “学” 的完全分离, 存在很多弊端。比如, 实践学 习脱离了理论学习, 学习效果不佳, 学生 在停课的状态下去企业参加实践, 在校学 习的时间被压缩, 那么势必会造成回校后 课程安排集中、学习压力大的情况。这种 情况下, 如果采取线上线下混合式教学方 式, 就会有不一样的效果。学生在学校学 习时采用线下混合式教学, 学生去企业实 习的阶段教师采用线上教学, 学生实习结 束回到课堂, 继续采用线下混合式教学。 这样的学习方式, 既能保证学生学习的系 统性, 理论联系实际, 提高学习效果, 也能 避免学生学习的不均衡性。

\section{[参考文献]}

[1]吴丽丽.线上线下混合式教学模 式的探索与实践一以《生活活动的组 织与实施》课程为例 [J]. 宁波教育学院 学报,2020,(01):11-12.

[2]傅沛蕾.基于云课堂的混合式课堂 教学模式实践研究—以《管理信息系统》 课程为例[J].通讯世界,2020,27(4):169-170.

[3]王爱华.基于混合式教学的 “职 业体验课程” 教学设计研究[J]. 江苏教 育研究,2020,(Z3):67-71.

\section{作者简介:}

王剑(1987--), 女, 汉族, 江苏扬州人, 本科,讲师,研究方向: 从事物流管理研究。 